\title{
Experimental and Numerical Investigation of Bed-Load Transport under Unsteady Flows
}

\author{
Gökçen Bombar, Ph.D. ${ }^{1}$; Şebnem Elçi²; Gokmen Tayfur; ${ }^{3}$ M. Şükrü Güney ${ }^{4}$; and Aslı Bor ${ }^{5}$
}

\begin{abstract}
The dynamic behavior of bed-load sediment transport under unsteady flow conditions is experimentally and numerically investigated. A series of experiments are conducted in a rectangular flume (18 $\mathrm{m}$ in length, $0.80 \mathrm{~m}$ in width) with various triangular and trapezoidal shaped hydrographs. The flume bed of $8 \mathrm{~cm}$ in height consists of scraped uniform small gravel of $D_{50}=4.8 \mathrm{~mm}$. Analysis of the experimental results showed that bed-load transport rates followed the temporal variation of the triangular and trapezoidal hydrographs with a time lag on the average of 11 and $30 \mathrm{~s}$, respectively. The experimental data were also qualitatively investigated employing the unsteady-flow parameter and total flow work index. The analysis results revealed that total yield increased exponentially with the total flow work. An original expression which is based on the net acceleration concept was proposed for the unsteadiness parameter. Analysis of the results then revealed that the total yield increased exponentially with the increase in the value of the proposed unsteadiness parameter. Further analysis of the experimental results revealed that total flow work has an inverse exponential variation relation with the lag time. A onedimensional numerical model that employs the governing equations for the conservation of mass for water and sediment and the momentum was also developed to simulate the experimental results. The momentum equation was approximated by the diffusion wave approach, and the kinematic wave theory approach was employed to relate the bed sediment flux to the sediment concentration. The model successfully simulated measured sedimentographs. It predicted sediment yield, on the average, with errors of $7 \%$ and $15 \%$ of peak loads for the triangular and trapezoidal hydrograph experiments, respectively. DOI: 10.1061/(ASCE)HY.1943-7900.0000412. @ 2011 American Society of Civil Engineers.
\end{abstract}

CE Database subject headings: Unsteady flow; Sediment transport; Bed loads; Parameters; Kinematic wave theory; Numerical models; Simulation.

Author keywords: Unsteady flow; Sediment transport; Bed load; Unsteadiness parameter; Work flow index; Time lag; Diffusion wave; Kinematic wave theory; Numerical model; Simulation.

\section{Introduction}

Bed load sediment transport has been widely studied under steady flow (Soni 1981; Yen et al. 1992; Yang 1996; Wilcock 2001) and unsteady-flow conditions (Wu and Wang 2004; Lee et al. 2004; Singh et al. 2004; Cui et al. 2005). Experiments conducted by several researchers provided an understanding of the sediment transport rate under unsteady-flow as compared to the steady flow conditions. Plate (1994) and Wang (1994) observed a lag time between the occurrence of peak discharge and that of the peak sediment transport rate, relating the lag to the bed's inertia. Reid et al. (1985) looked at the pattern of bed load in relation to the stream hydrograph for 11 floods at a stream close to London. With

\footnotetext{
${ }^{1}$ Post-doctoral Researcher, Civil Engineering Dept., Dokuz Eylul Univ., Tinaztepe, Izmir. E-mail: gokcenbombar2@gmail.com

${ }^{2}$ Assoc. Prof., Civil Engineering Dept., Izmir Inst. of Technology, Urla, Izmir. E-mail: sebnemelci@iyte.edu.tr

${ }^{3}$ Professor, Civil Engineering Dept., Izmir Inst. of Technology, Urla, Izmir (corresponding author). E-mail: gokmentayfur@iyte.edu.tr

${ }^{4}$ Professor, Civil Engineering Dept., Dokuz Eylul University, Tinaztepe, Izmir. E-mail: sukru.guney@deu.edu.tr

${ }^{5}$ Research Assistant, Civil Engineering Dept., Izmir Inst. of Technology, Urla, Izmir. E-mail: aslibor@iyte.edu.tr

Note. This manuscript was submitted on December 28, 2009; approved on February 23, 2011; published online on February 25, 2011. Discussion period open until March 1, 2012; separate discussions must be submitted for individual papers. This technical note is part of the Journal of Hydraulic Engineering, Vol. 137, No. 10, October 1, 2011. CASCE, ISSN 0733 9429/2011/10-1276-1282/\$25.00.
}

the first flood event after a long dry period, they also observed a lag time caused by loosening of material, resulting in higher bed load on the recession limb. On the contrary, when floods followed each other, they stated that a substantial amount of bed load was generated on the rising limb. Kuhnle (1992) pointed out the greater bed-load transport rates at high flows during the rising limb. De Sutter et al. (2001) supported this observation by suggesting that turbulence intensities, applying lift forces on sediment particles, are generally larger in the rising limb of a hydrograph than in the falling limb, possibly caused by the flood wave overtaking the base flow. Kuhnle (1992) stated that at low flows, transport rates were higher during the recession limb, and this was attributed to lag in formation and destruction of bed forms relative to the flow. Hassan et al. (2006) used a stepwise increase of discharge in their experiments investigating armoring in gravel bed rivers. They ran experiments with both symmetrical and asymmetrical hydrographs. In symmetrical experiments, they observed armoring where bed surface was coarser than the initial condition. In their short duration symmetrical experiment (about $1 \mathrm{~h}$ ), they observed a lag of time similar to that found by the other researchers.

An unsteadiness parameter defined by Graf and Suszka (1985) was used by the researchers to differentiate different hydrographs. Yen and Lee (1995) showed that the bed deformation was correlated to this parameter. Furthermore, regression relations for the transverse bed profile, transverse variation of sediment size, and total amount of sediment discharge were established in terms of the unsteady-flow parameter. De Sutter et al. (2001) discussed the effectiveness of this parameter and concluded that the unsteadiness parameter should include only the duration of the rising limb. 
Lee et al. (2004) investigated bed-load transport under unsteadyflow in a recirculating tilting flume. They found that sediment yield and peak rate under unsteady-flow conditions were, respectively, 1.6 and 1.4 times the predicted values, which were estimated based on the results obtained from steady-flow experiments. They also observed a difference of $6-15 \%$ between the flow hydrograph and sedimentograph.

Most of these existing unsteady transport studies have involved laying down the sediment over the channel bed and then passing mostly the constant or triangular-shaped hydrographs over the movable bed and measuring the transported sediment at the end of the channel (Lee et al. 2004). In this study, unsteady bed-load sediment transport under several triangular and trapezoidal shaped hydrographs was qualitatively investigated using the unsteadiness parameter and total flow work index. A new unsteadiness parameter based on the net acceleration concept was proposed.

Furthermore, this study a developed numerical model which can simulate bed-load sediment transport under unsteady-flow conditions subjected to any shape of sedimentograph feeding. As such, by this model, one would be able to numerically investigate and consequently gain more insight into understanding the physics of the process. There are many mathematical modeling studies of sediment transport in the literature, most of which, to close the system, have related sediment flux to flow variables, thus employing the dynamic or diffusion wave approaches ( $\mathrm{Wu}$ and Wang 2004; Singh et al. 2004). Tayfur and Singh (2006) were the first to employ the kinematic wave theory approach that constitutes a functional relation between sediment flux and sediment concentration. They tested their model against the diffusion wave model results and experimental data and showed the better performance of the kinematic wave theory model. Yet, for the model testing purpose, they employed the experimental aggradation data of Soni (1981) and, later on, aggradation and degradation data of Yen et al (1992), both of which are based on experiments under steady-flow conditions (see Tayfur and Singh 2006, 2007). This study tests the numerical model against experimental data obtained by the writers under unsteady-flow conditions.

\section{Experimental Setup and Experiments}

Experiments are carried out in a recirculating rectangular flume, located at Dokuz Eylul University (Izmir, Turkey) Hydraulics Laboratory, with a width of $80 \mathrm{~cm}$ and length of $18.6 \mathrm{~m}$. The transparent sides of the channel made from acrylic are $75 \mathrm{~cm}$ high. The slope of the flume is adjustable and set to 0.005 for this study. The volume of the water supply reservoir is $27 \mathrm{~m}^{3}$. During the experiments, the backwater effect at the downstream end was prevented by a tailgate. The steel channel's rigid bed is overlaid with an 8-cm-thick layer of uniform small gravel with $D_{50}=4.8 \mathrm{~mm}$ $\left(\sigma_{g}=1.4 ; D_{5}=2.2 \mathrm{~mm} ; D_{10}=2.4 \mathrm{~mm} ; D_{60}=5.4 \mathrm{~mm} ;\right.$ and $\left.D_{95}=7.7 \mathrm{~mm}\right)$. The uniformity coefficient $\left(C_{u}=D_{60} / D_{10}\right)$ of the soil that provides information about the homogeneity of soil granulation is calculated as $C_{u}=2.2$, implying that the sample is uniform.

The flow rate in the flume is controlled and preset by a speed control unit attached to a pump system with a maximum capacity of $100 \mathrm{~L} / \mathrm{s}$. The velocities are measured by an ultrasonic velocity profiler (UVP) that uses Doppler shift frequency. Hydrogen bubbles generated through electrolysis are used as scatterers in the water column because scatterers in tap water were not sufficient for accurate acoustic measurements. Flow velocity was obtained from depth averaging of velocity measurements after smoothing of the velocity data by the algorithm within Matlab. In the process, a $2 \mathrm{MHz}$ UVP was used to measure instantaneous velocities. During the steady flow experiments, the threshold value of shear stress for the initiation of sediment motion was obtained. UVP readings were also used to locate the flume bed which was defined as the point having measurement values of zero velocity and zero standard deviation.

At the downstream of the flume, the bed load is collected every $15 \mathrm{~s}$ using baskets composed of very fine meshed nets. Upon drying, the sediments are weighed to estimate the variation of total bed load with time. A series of triangular- and trapezoidal-shaped hydrographs were used in the experiments (Figs. 1 and 2). In triangular hydrographs (Runs \#1-5 and 8-11), flow was controlled to increase linearly from baseflow to peak discharge during a halfhydrograph period and then decrease linearly to baseflow in the second half-period. In trapezoidal hydrographs (Runs \# 6 and 7), maximum discharge of $68 \mathrm{~L} / \mathrm{s}$ is reached from the baseflow rate of $12 \mathrm{~L} / \mathrm{s}$ in $60 \mathrm{~s}$ in Run \#6 and in $300 \mathrm{~s}$ in Run \#7. At the beginning of each run, the bed was scraped with a flat plate attached to a steel rod to obtain the same initial elevation and consolidation of the flume bed. Then the bed was slowly filled with water to avoid the transport of bed material. Steady-state experiments were conducted prior to the runs, and baseflow was fixed based on the condition of the

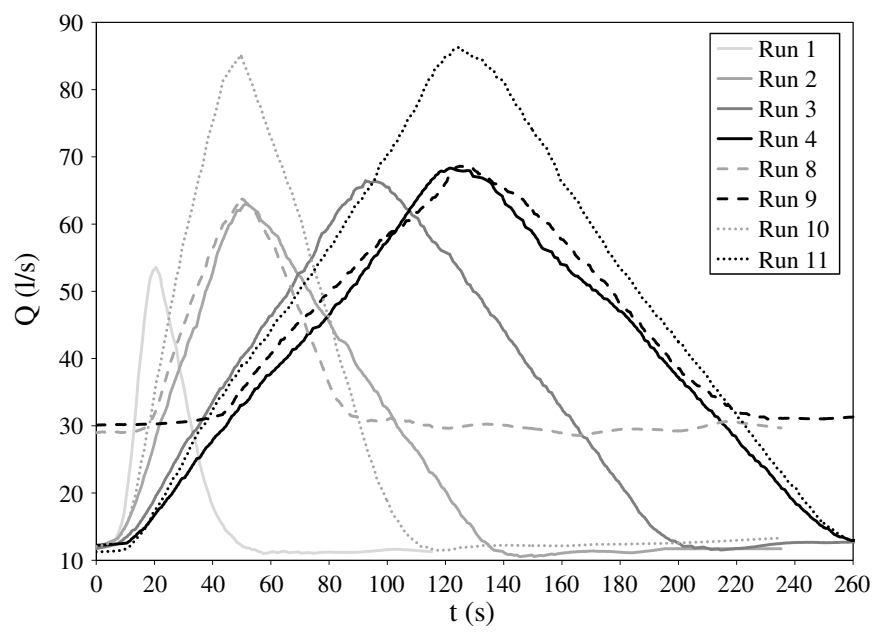

Fig. 1. Variation of discharge with time for different hydrographs (Runs \# 1-4 and 8-11)

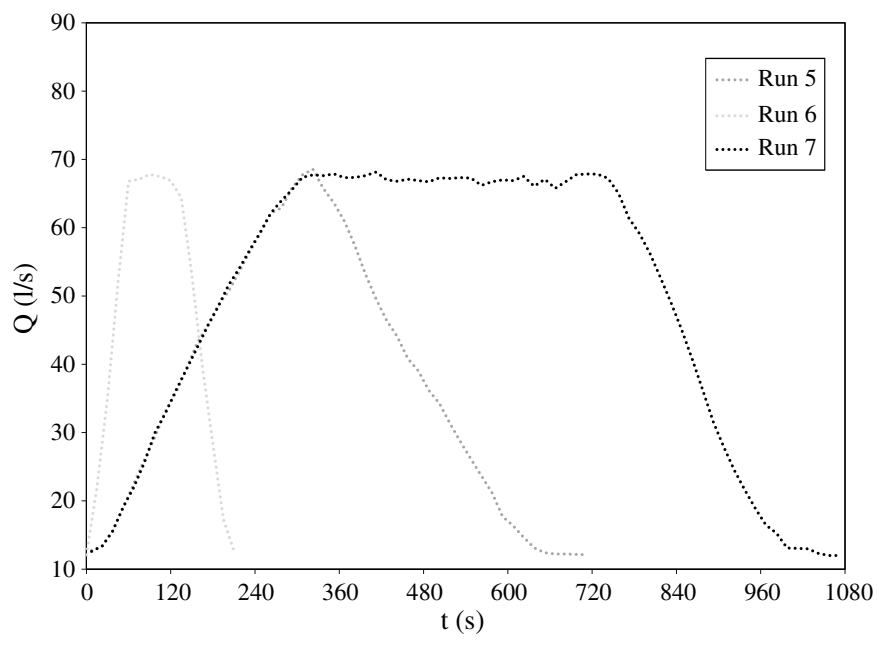

Fig. 2. Variation of discharge with time for different hydrographs (Runs \# 5, 6, and 7) 
incipient motion threshold. Following this, the desired hydrographs were obtained using the pump. Note that all runs were repeated at least twice, and total loads were in agreement in the replicated runs. However, all the parameters (flow depth, velocity, shear velocity) were measured in only one of the replicated experiments in each run and are discussed in this paper.

\section{Numerical Model}

One-dimensional unsteady bed-load transport equations, which are based on the conservation of mass for water and sediment and the dynamic momentum equation approximated by the diffusion wave, can be expressed as (Singh and Tayfur 2008)

$$
\begin{gathered}
\frac{\partial h}{\partial t}+\frac{\partial h u}{\partial x}+p \frac{\partial z}{\partial t}=0 \\
\frac{\partial h}{\partial x}+\frac{\partial z}{\partial x}=S_{o}-S_{f} \\
(1-p) \frac{\partial z}{\partial t}+\frac{\partial q_{b s}}{\partial x}=0
\end{gathered}
$$

where $h=$ flow depth $(L) ; u=$ flow velocity $(\mathrm{L} / \mathrm{T}) ; p=$ bed sediment porosity $\left(\mathrm{L}^{3} / \mathrm{L}^{3}\right) ; z=$ mobile bed layer elevation $(L) ; S_{o}=$ bed slope; $S_{f}=$ friction slope; $q_{b s}=$ sediment flux in the movable bed layer $\left(\mathrm{L}^{2} / \mathrm{T}\right) ; x=$ independent variable representing the coordinate in the longitudinal direction (flow direction) $(L)$; and $t=$ independent variable of time $(T)$. The system can be closed by employing, respectively, the Chezy's formulation for friction slope and the kinematic wave theory for the sediment flux (Tayfur and Singh 2006) as

$$
\begin{gathered}
u=C_{z} \sqrt{R S_{f}} \\
q_{b s}=(1-p) v_{s} z\left[1-\frac{z}{z_{\max }}\right]
\end{gathered}
$$

where $C z=$ Chezy's roughness coefficient, calculated from the following formula (Lindeburg 1992):

$$
C_{z}=\frac{R^{1 / 6}}{n}
$$

where $R=$ hydraulic radius; $n=$ Manning coefficient; $z=$ bed level $(L) ; z_{\max }=$ maximum bed level $(L)$; and $v_{s}=$ particle velocity $(\mathrm{L} / \mathrm{T})$.

For particle velocity $\left(v_{s}\right)$, the approach proposed by Chien and Wan (1999) can be employed

$$
v_{s}=u-\frac{\left(u_{c} / 1.4\right)^{3}}{u^{2}}
$$

where $u_{c}=$ critical flow velocity at the incipient sediment motion (L/T), computed following Yang (1996). Eqs. (5) and (7) were also employed by Tayfur and Singh (2006, 2007), Singh and Tayfur (2008), and Bor (2008).

The system of equations is solved using the Lax finite difference method. Numerical stability is maintained using the following condition, resulting in an adaptive time scheme:

$$
C_{n}=\frac{(u+\sqrt{g h}) \Delta t}{\Delta x} \leq 1
$$

where $C_{n}=$ Courant stability condition coefficient; $\Delta t=$ numerical time step; $\Delta x=$ numerical space step; and $g=$ gravitational acceleration. Parameters used in the numerical model are consistent with the experiments where a channel with a length of $18 \mathrm{~m}$, a width of $0.80 \mathrm{~m}$, and slope of 0.005 is modeled, porosity is taken as 0.4 , and sediment density and size are set to $2,640 \mathrm{~kg} / \mathrm{m}^{3}$ and $4.8 \mathrm{~mm}$, respectively. The initial water depth is set to baseflow depth and initial elevation of the bed is set to $8 \mathrm{~cm}$. At the upstream boundary, the inflow hydrograph and sedimentograph were specified, and a Neumann boundary condition (zero gradient) is applied for the downstream boundaries. In the simulations, the space step $\Delta x$ is taken as $0.10 \mathrm{~m}$.

\section{Analysis of Results}

\section{Experimental Results}

Results of the experiments showed that bed-load transport rates followed the temporal variation of the triangular and trapezoidal hydrographs with a time lag on the average of 11 and $30 \mathrm{~s}$,

Table 1. Parameters Estimated from Various Hydrographs

\begin{tabular}{lrrrrrrrrrrrrrrrrrrrrrrr}
\hline Run no. & \multicolumn{1}{c}{$t_{r}$} & \multicolumn{1}{c}{$t_{d}$} & \multicolumn{1}{c}{$t_{s p}$} & $t_{\mathrm{lag}} / t_{r}$ & $y_{0}$ & $y_{p}$ & $u_{* 0}$ & $u_{* p}$ & $W_{R}$ & $W_{F}$ & $W_{R} / W_{F}$ & $W_{R} / W_{t}$ & $u_{0}$ & $u_{p}$ & Vol. & $P$ & $P_{\bmod }$ & $P_{g t}$ & $W_{k}$ & $W_{t}$ & $W_{t} *$ \\
\hline 1 & 14 & 67 & 22.5 & 0.61 & 0.04 & 0.09 & 0.04 & 0.07 & 400 & 427 & 0.94 & 0.48 & 0.38 & 0.77 & 0.26 & 0.016 & 0.007 & 0.0021 & 0.4 & 0.8 & 15.4 \\
2 & 46 & 150 & 67.5 & 0.47 & 0.04 & 0.10 & 0.04 & 0.07 & 1256 & 1611 & 0.78 & 0.44 & 0.38 & 0.78 & 1.41 & 0.009 & 0.004 & 0.0041 & 1.9 & 2.9 & 59.0 \\
3 & 90 & 208 & 97.5 & 0.08 & 0.04 & 0.10 & 0.04 & 0.07 & 1737 & 2213 & 0.79 & 0.44 & 0.38 & 0.80 & 2.50 & 0.007 & 0.002 & 0.0045 & 3.4 & 4.0 & 80.9 \\
4 & 119 & 267 & 127.5 & 0.07 & 0.04 & 0.10 & 0.04 & 0.07 & 2499 & 2755 & 0.91 & 0.48 & 0.38 & 0.83 & 3.38 & 0.005 & 0.001 & 0.0046 & 4.7 & 5.3 & 107.5 \\
5 & 300 & 645 & 322.5 & 0.08 & 0.04 & 0.11 & 0.04 & 0.07 & 7164 & 5098 & 1.41 & 0.58 & 0.38 & 0.79 & 8.50 & 0.002 & 0.001 & 0.0049 & 11.7 & 15.3 & 313.6 \\
$6^{a}$ & 60 & 210 & 82.5 & 0.38 & 0.04 & 0.11 & 0.04 & 0.07 & 2262 & 1869 & 1.21 & 0.55 & 0.38 & 0.79 & 4.16 & 0.007 & 0.003 & 0.0043 & 5.7 & 8.0 & 163.8 \\
$7^{\mathrm{a}}$ & 300 & 990 & 337.5 & 0.13 & 0.04 & 0.11 & 0.04 & 0.07 & 7180 & 4356 & 1.65 & 0.62 & 0.38 & 0.79 & 23.47 & 0.002 & 0.001 & 0.0049 & 32.3 & 41.9 & 857.2 \\
8 & 34 & 99 & 38.5 & 0.13 & 0.07 & 0.10 & 0.06 & 0.07 & 922 & 1093 & 0.84 & 0.46 & 0.57 & 0.79 & 1.27 & 0.006 & 0.001 & 0.0043 & 1.7 & 2.0 & 40.9 \\
9 & 82 & 187 & 89.5 & 0.09 & 0.07 & 0.10 & 0.06 & 0.07 & 1887 & 2452 & 0.77 & 0.43 & 0.57 & 0.83 & 3.73 & 0.003 & 0.000 & 0.0047 & 5.1 & 4.3 & 88.9 \\
10 & 44 & 136 & 52.5 & 0.19 & 0.04 & 0.12 & 0.04 & 0.08 & 1877 & 2411 & 0.78 & 0.44 & 0.38 & 0.90 & 2.20 & 0.013 & 0.006 & 0.0038 & 3.0 & 4.3 & 87.8 \\
11 & 118 & 270 & 127.5 & 0.08 & 0.04 & 0.12 & 0.04 & 0.08 & 4755 & 4843 & 0.98 & 0.50 & 0.38 & 0.90 & 5.21 & 0.007 & 0.002 & 0.0046 & 7.2 & 9.6 & 196.5 \\
\hline
\end{tabular}

Note: $t_{r}=$ time to peak rate of hydrograph $(s) ; t_{d}=$ duration of hydrograph $(s) ; t_{s p}=$ time to peak rate of sedimentograph $(s) ; t_{\text {lag }}=$ difference between peak times $\left(t_{s p}-t_{r}\right)(s) ; y_{0}=$ water depth at base flow $(m) ; y_{p}=$ water depth at peak flow $(m) ; u_{* 0}=$ shear velocity at base flow $(m / s) ; u_{* p}=$ shear velocity at peak flow $(\mathrm{m} / \mathrm{s}) ; W_{R}=$ total bed load collected during the rising stage $(\mathrm{g}) ; W_{F}=$ total bed load collected during the recession stage $(\mathrm{gr}) ; u_{0}=$ velocity of the base flow hydrograph $(\mathrm{m} / \mathrm{s}) ; u_{p}=$ velocity of the peak flow hydrograph $(\mathrm{m} / \mathrm{s}) ;$ Vol. $=$ total volume of water under the hydrograph $\left(\mathrm{m}^{3}\right) ; \mathrm{P}=$ unsteady-flow parameter; $P_{\text {mod }}=$ modified unsteady-flow parameter; $P_{g t}=$ proposed unsteady-flow parameter; $W_{k}=$ total flow work; Wt $=$ total bed load $(\mathrm{kg}) ; W_{t} *=$ dimensionless total bed load.

${ }^{a}$ Runs \#6 and \#7 refer to trapezoidal hydrographs, and the rest refer to triangular hydrographs. 
respectively. Evaluation of total sediment yield corresponding to rising and recession limbs showed that total sediment yield for the recession stage was higher than the rising stage in triangular hydrographs, whereas total sediment yield was higher at the recession stage in trapezoidal hydrographs. Table 1 summarizes parameters calculated from the experiments which were utilized to analyze the unsteadiness character of the transport.

\section{Unsteadiness Parameter and Total Flow Work Index}

Although many empirical sediment transport formulations exist in the literature, application of these relationships to unsteady phenomena might give erroneous results because of accelerations in the unsteadiness character of the problem. In the literature, the unsteadiness character of the flow is investigated through the unsteady flow parameter $(P)$ and total flow work $\left(W_{k}\right)$ (Graf and Suzka 1985; Yen and Lee 1995; Song and Graf 1997; Lee et al. 2004). The sediment transport rate, $q_{s}$, is considered to be a function of these parameters that are expressed as (Lee et al. 2004)

$$
\begin{gathered}
P=\frac{h_{p}-h_{0}}{t_{d} u_{* 0}} \\
W_{k}=\frac{u_{* 0}^{2} V_{o l}}{g h_{0}^{3} B}
\end{gathered}
$$

where $B=$ channel width; $V_{o l}=$ total volume of water under the hydrograph (excluding the baseflow); $u_{* 0}=$ shear velocity of the baseflow at the upstream end calculated as a function of slope and hydraulic radius; $h_{0}=$ initial flow depth (baseflow) at the upstream end; $h_{p}=$ flow depth at the peak of the hydrograph at the upstream end; and $t_{d}=$ duration of the hydrograph.

De Sutter et al. (2001) discussed the effectiveness of the unsteadiness parameter with respect to the duration of both the rising and descending limbs. They stated that only the duration of the rising limb should be considered in the unsteadiness of the hydrograph and proposed the following parameter instead:

$$
P=\frac{h_{p}-h_{0}}{t_{r}\left[\left(u_{o}+u_{p}\right) / 2\right]} \frac{u_{* p}^{2}-u_{* c r}^{2}}{u_{* c r}^{2}}
$$

where $t_{r}=$ duration of the rising limb; $u_{* p}=$ shear velocity at peak flow, calculated as a function of slope and hydraulic radius at the peak stage; $u_{* c r}=$ critical shear velocity; and $u_{o}$ and $u_{p}=$ velocities of the baseflow and peak hydrograph. Table 1 summarizes the parameters estimated from the hydrographs.

When nondimensionalized total bed load $W_{t} *\left(=W_{t} / \rho_{s} B D_{50}^{2}\right.$, where $W_{t}=$ total bed load collected during the whole experimental period; and $\rho_{s}=$ sediment mass density) is plotted against the unsteadiness parameter $P$, an exponential inverse variation is observed with $R^{2}=0.50$ (see Fig. 3). Similarly, one can see the weak variation relation between $P_{\text {mod }}$ and $W_{t}^{*}$ in Fig. $4\left(R^{2}=0.22\right)$. These results are contrary to those obtained by Lee et al. (2004), who observed a direct variation between $P$ and $W_{t}$ for hydrographs whose durations ranged from $1,260 \mathrm{~s}$ to $4,800 \mathrm{~s}$. In our experiments, durations of hydrographs were much shorter and varied from $67 \mathrm{~s}$ to $645 \mathrm{~s}$ for the triangular hydrographs. Nevertheless, the inverse variation relation between $P$ and $W_{t}$ (or between $P_{\text {mod }}$ and $\left.W_{t}\right)$ implies that, as unsteadiness increases, the total load carried by the flow decreases. This may not be the situation in nature. No matter the durations and/or magnitudes of hydrographs, we would expect an increase in transported load with an increase in the unsteadiness of the flow, also pointed out by De Sutter et al.(2001). An unsteady regime causes resuspension and transport of deposited bottom sediments. This is because turbulence intensities, both streamwise and vertical, are larger in unsteady flows,

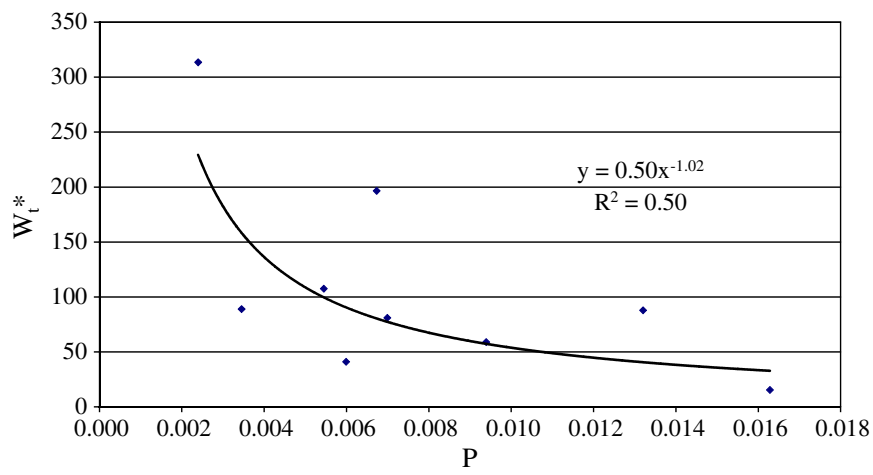

Fig. 3. Variation of unsteadiness parameter, $P$, with nondimensionalized total bed load, $W_{t}{ }^{*}$

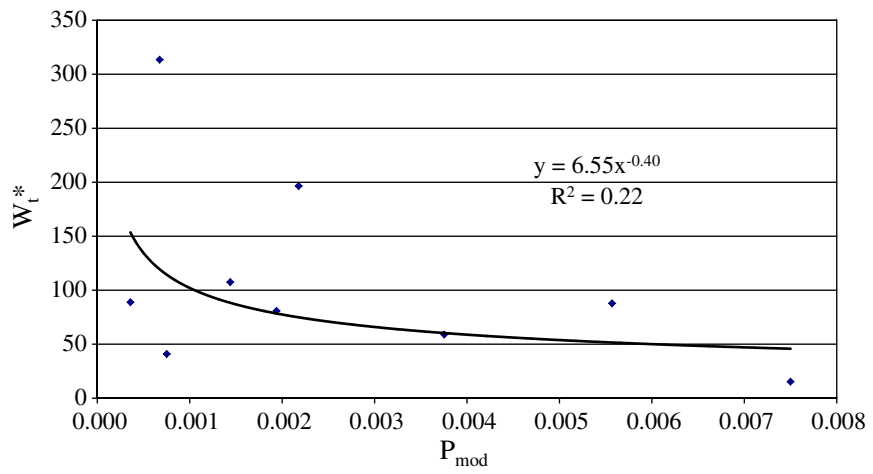

Fig. 4. Variation of modified unsteadiness parameter, $P$, with nondimensionalized total bed load, $W_{t}{ }^{*}$

causing lift forces on sediment particles. According to Graf (2003), turbulence plays an essential role in all flows of watersediment mixtures.

This finding has forced us to come to the conclusion that Eqs. (9) and (11) may not be proper expressions to describe the unsteadiness effects of a flow, either for short-duration hydrographs or for the experiments carried out in this study. Therefore, in this study, we propose the following formulation for expressing the unsteadiness parameter. Based on the concept of net acceleration in the rising period of the hydrograph, as suggested by De Sutter et al. (2001), and by nondimensionalizing it with the gravitational acceleration, the proposed unsteadiness parameter $\left(P_{g t}\right)$ can be expressed as

$$
P_{g t}=\frac{\left|g S_{o}-\left(\frac{u_{p}-u_{o}}{t_{r}}\right)\right|}{g}
$$

In Eq. (12), the numerator stands for the net acceleration during the rising period of the hydrograph. Note that Eq. (12) conceptually differs from Eqs. (9) and (11) in the sense that it employs directly the concept of net acceleration in the flow resulting from the rising limb and, for computing the acceleration, it directly uses the measured flow velocities at peak and baseflow conditions. Plotting of the variation between $P_{g t}$ and $W_{t}^{*}$ indicated, that as unsteadiness increases, the sediment transport capacity of the flow increases, conforming to natural conditions and results of studies in the literature. The best fit correlation equation between the parameters is obtained, with $R^{2}=0.66$, as

$$
W_{t}^{*}=2.29 \exp \left(855.3 P_{g t}\right)
$$

Fig. 5 shows the variation between the dimensionless total bed load and total flow work. As seen, there is a strong linear variation 


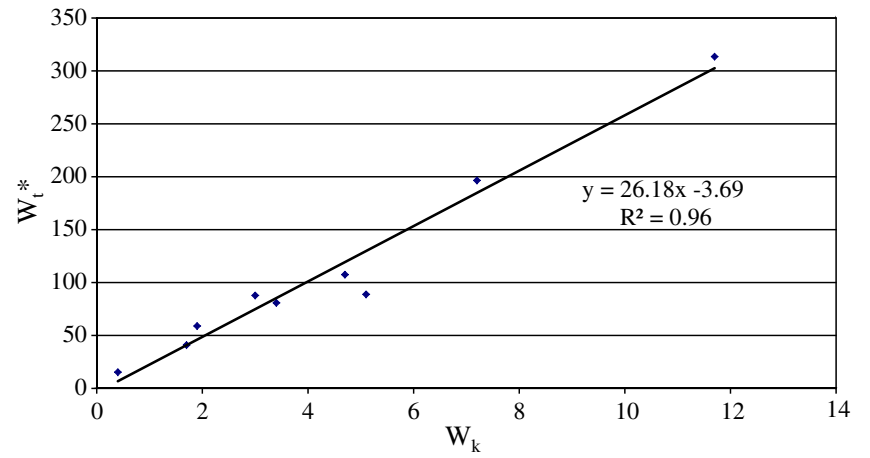

Fig. 5. Variation of nondimensionalized total bed load, $W_{t}{ }^{*}$, with total flow work, $W_{k}$

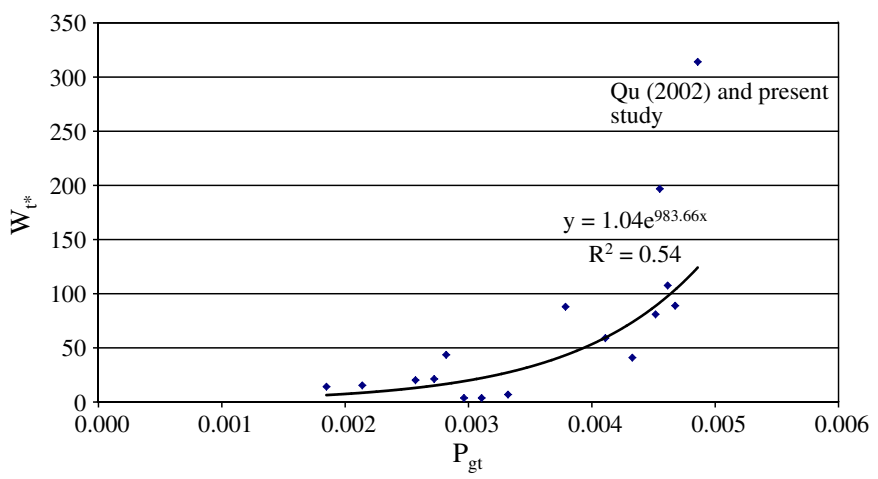

Fig. 6. Variation of nondimensionalized total bed load, $W_{t}^{*}$, with proposed unsteadiness parameter, $P_{g t}$, for present study and Qu (2002)

between the two variables with $R^{2}=0.96$. The best fit correlation equation between the two variables for Fig. 5 is obtained as

$$
W_{t}^{*}=26.18 W_{k}+3.69
$$

For the verification of the proposed parameter, $P_{g t}$, the parameter was tested with an independent set of data with different bed slope. The bed slope used in the experiments conducted by Qu (2002) was 0.003 , whereas in our experiments, we utilized a bed slope of 0.005 . Correlation of $P_{g t}$ to $W_{t}^{*}$ was observed (the $R^{2}$ value was 0.54 ) when data from these two independent studies were plotted together (Fig. 6), indicating that net acceleration in the flow resulting from the rising limb has influence on the total bed load, which increases as unsteadiness increases.

Another interesting result is obtained from the investigation of the nondimensionalized lag times of sedimentograph and hydrograph peaks for unsteadiness, as presented in Fig. 7. As seen, there is an inverse variation relation between lag time and the unsteadiness parameter, with a correlation coefficient of $R^{2}=0.96$. This implies that lag time decreases exponentially as unsteadiness increases. This is a plausible result bacause unsteadiness increases transport capacity of the flow and, consequently, the total flow work. Unsteadiness, in turn, is higher in short-duration experiments, as presented in the experimental works of Lee et al. (2004), who pointed out that the lag time between the hydrograph and sedimentograph peaks was about $6 \%$ in short duration experiments (UA-series), whereas it was about $15 \%$ in longer duration experiments (UB-series). Also, as pointed out previously, De Sutter et al. (2001) showed that shorter rising limb hydrographs have higher values of unsteadiness.

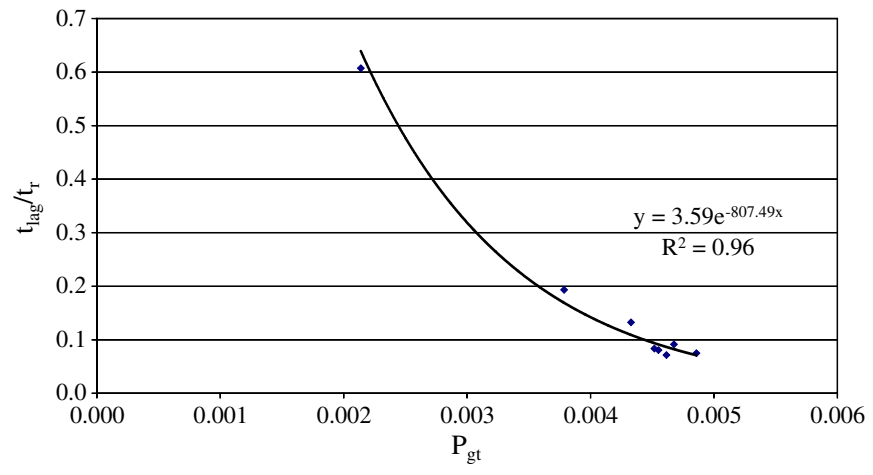

$\underline{\text { Fig. 7. Variation of lag time, } t_{\mathrm{lag}} / t_{r} \text {, with unsteadiness parameter, } P_{g t}}$

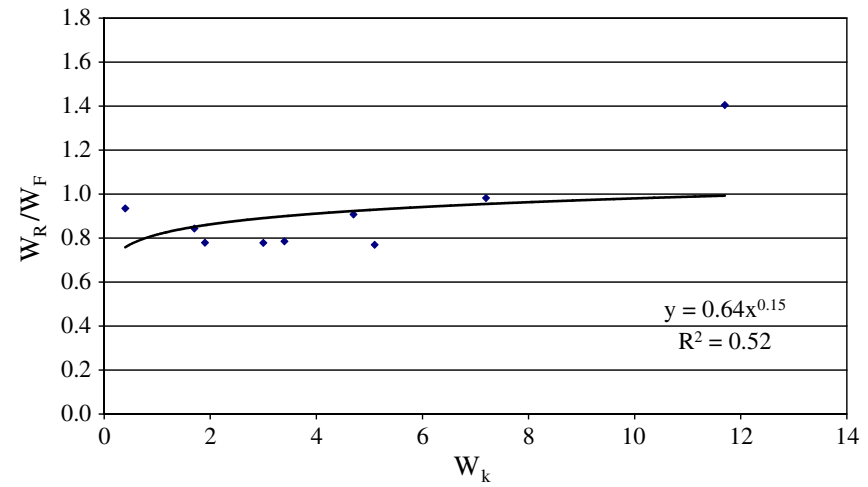

Fig. 8. Variation of total flow work, $W_{k}$, with ratio of total bed load collected during rising stage, $W_{R}$, to recession stage, $W_{F}$

Total sediment yields corresponding to rising and recession limbs are calculated and provided in Table 1. Results showed that, in almost all triangular hydrographs, total sediment yield for the recession stage was higher than for the rising stage. Fig. 8 shows the relationship between the total flow work and the ratio of total bed load collected during the rising stage to recession stage. This figure indicates that the total bed load in the rising stage increases with total flow work.

\section{Simulation of Experimental Results}

The numerical model used in this study simulated sediment yield resulting from triangular (Run \#5 ) and trapezoidal (Run \#7) hydrographs as illustrative examples. Fig. 9 presents satisfactory simulations of sediment yield measured during the triangular shape inflow hydrograph. The model has captured the observed profiles closely. The root mean square error (RMSE) for this simulation was $70 \mathrm{~g}$, corresponding to $6 \%$ of the peak load observed, and the mean absolute error (MAE) was $46 \mathrm{~g}$. The model simulations show that there is no lag between hydrograph and sedimentograph, at least at the maxima. However, sediment flux was plotted against water discharge for both the observed and simulated data, and a narrowshaped hysteresis for both were observed, implying retardation.

Fig. 10 presents simulations of sediment rates measured during a trapeziodal inflow hydrograph. As seen, the model satisfactorily simulated the rising and recession limbs of the sedimentographs. However, the model underpredicted the constant period of the sedimentographs. While the model produced a constant rate, the measured data show a gradual decrease during this period. This may be because looser and finer sediments were transported first. In the above simulations, however, the bed material was assumed to be 


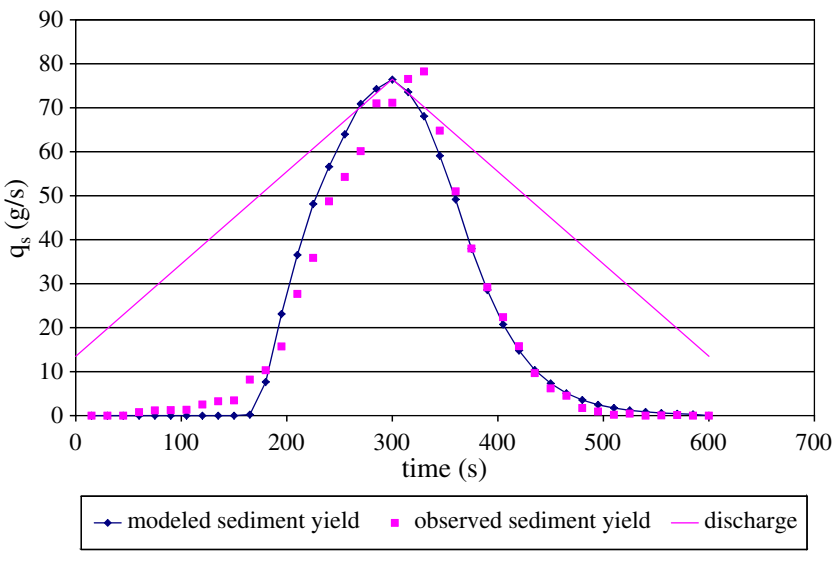

Fig. 9. Comparison of numerically modeled and observed sediment yield at downstream of flume after triangular hydrograph

composed of strictly uniform small gravel, i.e., a constant value of $D_{50}=4.8 \mathrm{~mm}$ particle size was employed in the simulations.

To consider the change in the sediment composition of the material, the numerical model was modified to transport a mixture of sediments. The governing equations for the transport of a sediment mixture as a bed load can be expressed as (Armanini and di Silvio 1988; Wu and Wang 2004)

$$
\begin{gathered}
\frac{\partial h}{\partial t}+\frac{\partial h u}{\partial x}+\sum_{i=1}^{N} p_{i}\left(\frac{\partial z}{\partial t}\right)=0 \\
\frac{\partial h}{\partial x}+\sum_{i=1}^{N}\left(\frac{\partial z}{\partial x}\right)_{i}=S_{o}-S_{f} \\
\left(1-\sum_{k=1}^{N} p_{i}\right) \frac{\partial z}{\partial t}+\sum_{i=1}^{N}\left(\frac{\partial q_{b s}}{\partial x}\right)_{i}=0
\end{gathered}
$$

where $N=$ number of different materials in the mixture. A multiple layer model for bed material sediment composition (where 34\% is set to $4.1 \mathrm{~mm}$, another $34 \%$ is $5.5 \mathrm{~mm}, 16 \%$ is $7.0 \mathrm{~mm}$, and another $16 \%$ is $2.8 \mathrm{~mm}$ ) is considered. Employing a mixture of sediments as bed material instead of using only the mean constant value improved the results significantly (Fig. 10). The RMSE was

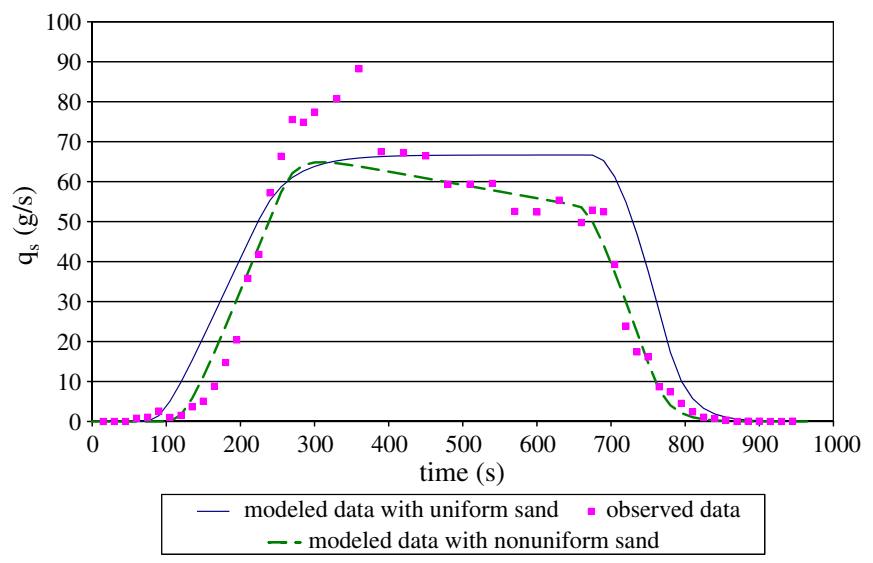

Fig. 10. Comparison of numerically modeled sediment yield with uniform and nonuniform bed material with observed sediment yield at downstream of flume after trapezoidal hydrograph calculated as $430 \mathrm{~g}$, corresponding to $14 \%$ of the peak load observed, and the MAE was $205 \mathrm{~g}$.

\section{Conclusions}

A series of triangular and trapezoidal hydrograph experiments was carried out to study bed-load transport under unsteady-flow conditions. The comparison of observed hydrographs and related sedimentographs showed that there were time lags on the average of $11 \mathrm{~s}(4 \%$ of the rising time period) and $30 \mathrm{~s}$ (10\% of the rising time) between the peaks of the flows and sediment loads for the triangular and trapezoidal hydrograph experiments, respectively. This is in agreement with the findings in the literature.

The unsteadiness effect of the flow on the transport of the bed load was also quantitatively studied, employing the unsteadiness and total flow work parameters. The total load (or the transport capacity) exponentially increased as the value of the total flow work parameter increased, conforming to the findings in the literature. However, the unsteadiness parameter, expressed in the literature by Eq (9), did not yield realistic results. It showed an exponentially decreasing trend with the total load transport. Hence, in this study, for the experimental results, we proposed an alternative unsteadiness parameter, which is expressed by Eq. (12). This original expression is based on the net acceleration concept, using directly the flow velocity measurements at peak and baseflow conditions. In that sense, it differs from the existing equations that employ the flow velocity concept, using the observed flow depths. The proposed formulation for the unsteadiness parameter yielded plausible results for the experimental data not only in this study but also with another different set of data. In accordance with the literature, experimental observations in this study showed a strong inverse variation relation between lag time and total flow work.

The numerical model successfully simulated the experimental runs consisting of different-shaped triangular and trapezoidal inflow hydrographs. The model predicted sediment yield, on the average, with errors of $7 \%$ and $15 \%$ of peak loads for the triangular and trapezoidal hydrograph experiments, respectively. In order to better simulate the equilibrium phase (constant loading period) of the trapezoidal sedimentograph, the model had to consider the change in the sediment composition and thus, transport of the mixture of sediment.

\section{Acknowledgments}

This study was funded by research grants from TUBITAK through the Project No: 106M274. We also would like to express gratitude to Prof. Dr. Turhan Acatay for his support and guidance during both the planning and execution of the experiments. Finally, we would like to thank graduate student Erdi Aydöner and technician Isa Üstündağ for their help during the execution of the experiments.

\section{References}

Armanini, A., and di Silvio, G. (1988). "A one-dimensional model for the transport of a sediment mixture in nonequilibrium conditions." J. Hydraul. Res., 26(3), 275-292.

Bor, A. (2008). "Numerical modeling of unsteady and nonequilibrium sediment transport in rivers." M.Sc. thesis, Dept. of Civil Engineering, Izmir Inst. of Technology, Urla, Izmir.

Chien, N., and Wan, Z. H. (1999). Mechanics of sediment transport, ASCE, Reston. Va.

Cui, Y., Parker, G., Lisle, T. E., Pizzuto, J. E., and Dodd, A. M. (2005). "More on the evolution of bed material waves in alluvial rivers." Earth Surf. Processes Landforms, 30, 107-114. 
De Sutter, R., Verhoeven, R., and Krein, A. (2001). "Simulation of sediment transport during flood events: Laboratory work and field experiments." Hydrol. Sci. J., 46(4), 599-610.

Graf, W. H. (2003). Fluvial hydraulics: Flow and transport processes in channels of simple geometry, Wiley, New York.

Graf, W. H., and Suszka, L. (1985). "Unsteady flow and its effect on sediment transport." Proc., 21st IAHR Congr., Melbourne, Australia, Int. Assoc. for Hydro-Environment Eng. and Res., 540-544.

Hassan, M. A., Egozi, R., and Parker, G. (2006). "Experiments on the effect of hydrograph characteristics on vertical grain sorting in gravel bed rivers." Water Resour. Res., 42(9), 1-15.

Kuhnle, R. A. (1992). "Bed-load transport during rising and falling stages on two small streams." Earth Surf. Processes Landforms, 17(2), 191-197.

Lee, K. T., Liu, Y. L., and Cheng, K. H. (2004). "Experimental investigation of bed-load transport processes under unsteady flow conditions." Hydrol. Processes, 18(13), 2439-2454.

Lindeburg, M. R. (1992). Engineer in training reference manual, 8th Ed., Professional Publications, Belmont, CA.

Plate, E. J. (1994). "The need to consider nonstationary sediment transport." Int. J. Sediment Res., 9, 117-123.

Qu, Z. (2002). "Unsteady open-channel flow over a mobile bed." Ph.D. thesis, No. 2688, École Polytechnique Fédérale de Lausanne, Lausanne, Switzerland.

Reid, I., L. Frostick, E., and Layman, J. T. (1985). "The incidence and nature of bed-load transport during flood flows in coarse-grained alluvial channels." Earth Surf. Processes Landforms, 10(1), 33-44.
Singh, V. P., and Tayfur, G. (2008). "Kinematic wave theory for transient bed sediment waves in alluvial rivers." J. Hydrol. Eng., 13(5), 297-304.

Singh, A. K., Kothyari, U. C., and Raju, K. G. R. (2004). "Rapidly varying transient flows in alluvial rivers." J. Hydraul. Res., 42(5), 473-486.

Song, T., and Graf, W. H. (1997). "Experimental study of bed-load transport in unsteady open-channel flow." Int. J. Sediment Res., 12,63-71.

Soni, J. P. (1981). "Laboratory study of aggradation in alluvial channels." J. Hydrol. (Amsterdam),49(1-2), 87-106.

Tayfur, G., and Singh, V. P. (2006). "Kinematic wave model of bed profiles in alluvial channels." Water Resour. Res., 42, W06414-W06426.

Tayfur, G., and Singh, V. P. (2007). "Kinematic wave model for transient bed profiles in alluvial channels under nonequilibrium conditions." Water Resour. Res., 43, W12412-W12422.

Yang, C. T. (1996). Sediment transport: Theory and practice, McGrawHill, New York.

Yen, C. L., and Lee, K. T. (1995). "Bed topography and sediment sorting in channel bend with unsteady flow." J. Hydraul. Eng., 121(8), 591-599.

Yen, C. L., Chang, S. Y., and Lee, H. Y. (1992). "Aggradation degradation process in alluvial channels." J. Hydraul. Eng., 118(12), 1651-1669.

Wang, Z. (1994). "An experimental study of motion and deposition of gold particles in a mountain river." J. Hydraul. Res., 32(5), 643-648.

Wilcock, P. R. (2001). "Toward a practical method for estimating sedimenttransport rates in gravelbed rivers." Earth Surf. Processes Landforms, 26(13), 1395-1408.

Wu, W., and Wang, S. S. Y. (2004). "Depth-averaged 2-D numerical modeling of unsteady flow and nonuniform sediment transport in open channels." J. Hydraul. Eng., 130(10), 1013-1024. 